\title{
Pulmonary effects and disposition of luteolin and Artemisia afra extracts in isolated perfused lungs
}

Sizwe Joel Mjiqiza, James Abraham Syce, Kenechukwu Chibuzo Obikeze

\begin{abstract}
Ethnopharmacological relevance: Artemisia afra (Asteraceae) is a traditional medicinal plant frequently used in steam inhalation form to treat respiratory conditions.

Aim of the study: Quantify luteolin content in Artemisia afra dried crude and aqueous extract. Evaluate the pulmonary effects of Artemisia afra steam inhalation, nebulized Artemisia afra extract and luteolin in isolated perfused lungs (IPL). Evaluate the pulmonary disposition of intravenously administered luteolin. Materials and methods: HPLC was used to quantify luteolin in Artemisia afra extracts. A modified version of the IPL was used to determine the effects of Artemisia afra steam inhalation, nebulized luteolin, and nebulized aqueous leaf extract on lung function, as well as the pulmonary disposition of IV luteolin.

Results: Artemisia afra extract contained significantly higher luteolin levels than the crude dried leaves. Inhaled Artemisia afra steam, and nebulized luteolin, and Artemisia afra extract and IV luteolin produced significant dosedependent improvements in lung function, with nebulized Artemisia afra producing the greatest improvements. Nebulisation with Artemisia afra extract yielded higher quantities of luteolin than luteolin nebulisation.

Conclusion: Results verify the traditional use of inhalation of Artemisia afra steam, although nebulized luteolin and aqueous extract are better alternatives. Luteolin significantly contributes to the broncho-dilatory effects of Artemisia afra.
\end{abstract}

\section{Introduction}

Traditional medicines remain a source of viable alternatives for affordable healthcare especially in developing countries (Mayosi et al., 2009). In South Africa an estimated 70\% of the population depend on traditional medicines largely comprising of plants such as Artemisia afra Jacq. ex Willd (Asteraceae) for treatment of a wide variety of diseases (Mander et al., 1997).

Artemisia afra, a multi-stemmed perennial shrub with greyish- green feathery leaves, enjoys widespread use in traditional med- icines in South Africa for the treatment of a 
wide variety of illnesses. The most prevalent use is for the treatment of respiratory disorders such as coughs, colds, bronchitis, blocked sinuses and tight-chest or asthma in the form of a steam inhalation of the leaves (Roberts, 1990; Iwu, 1993; Van Wyk and Gerike, 2000a). Extracts of the plant leaves have been shown to exhibit various pharmacological effects including relaxation of respiratory smooth muscles contracted by various known bronco-constrictors, but the bronchodilatory effect of the plant in the form that it is used in traditional medicine (steam inhalation) is yet to be assessed in intact lungs and the exact plant chemical constituents responsible for this activity is still unknown (Roberts, 1990; Van Wyk and Gerike, 200ob; Waithaka, 2004).

Flavonoids, found in appreciable quantities in Artemisia afra, have been suggested to be responsible for the bronchodilatory effect of the extracts (Harris, 2002). Artemisia afra contains several flavonoids, including apigenin, chrysoeriol, tamarixetin, acacetin, genkwanin and kaempferol (Kraft et al., 2003; Waithaka, 2004; Avula et al., 2009) with the aqueous extract containing greater quantities of luteolin and quercetin than the other flavonoids (Muganga, 2004; Waithaka, 2004; Mukinda et al., 2010). These 2 flavonoids are also easily extractable from the plant, stable under various processing conditions, and selectively quantifiable using HPLC, thus making them ideal markers when evaluating Artemisia afra extracts, (Markam, 1982; Harborne and Williams, 2000; Waithaka, 2004; Springfield et al., 2005, Mukinda et al., 2010). Luteolin however with its greater quantities (Muganga, 2004; Waithaka, 2004), anti-inflammatory, antispasmodic (Yamazaki et al., 2002), and muscle relaxant activity (Sanchez de Rojas et al., 1995; Harris, 2002; Das et al., 2003) is the ideal candidate for a marker compound.

Although the pharmacokinetics and bioavailability of luteolin has been studied using various models, the pharmacokinetics following pulmonary administration is yet to be carried out (Shimoi et al., 1998; Spencer et al., 1999; Scalbert and Williamson, 2000; Wang et al., 2003; Muganga, 2004; Lui et al., 2005, Mukinda et al., 2010). To study the pharmacokinetics of luteolin in the lungs as well as the effects of Artemisia afra on lung parameters, the isolated perfused lung (IPL) model was chosen. It provides a suitable model for measuring the delivery and pharmacokinetics of Artemisia afra in the lungs as well as the effect on pulmonary parameters such as lung resistance and compliance whilst mini- mizing the influence of the nervous system, hormones, and chemical mediators circulating in plasma. It also allows for the simultaneous measurement of respiratory mechanics such as tidal volume, lung compliance, and resistance and can easily be adapted for administration via inhalation, instillation, bolus injection or continuous perfusion (Uhlig and Wollin, 1994; Uhlig and Taylor, 1998; Mjiqiza, 2006).

In this study, the isolated perfused lung (IPL) model was used to evaluate the pulmonary effects of the traditionally-prepared Artemisia afra steam inhalation, nebulized Artemisia afra aqueous extract and luteolin solutions. Luteolin content in dried crude Artemisia afra leaves and an aqueous extract of Artemisia afra leaves were quantified using HPLC and the pulmonary disposition and effect of intravenously administered luteolin in IPL determined. 


\section{Materials and methods \\ 2.1Chemicals and reagents}

Sodium chloride, potassium chloride, calcium chloride 2-hydrate, potassium dihydrogen phosphate, magnesium chloride 6-hydrate, sodium hydrogen carbonate and glucose (all of analytical grade; Holpro Analytics Pty Ltd., Johannesburg, South Africa); bovine serum albumin (Fraction V), luteolin (97\%) and dimethyl sulfoxide ( all Sigma-Aldrich, South Africa, Vorna Valley, South Africa); heparin sodium (Fresenius Kabi (Pty) Ltd., Cape Town, South Africa); sodium pentobarbitone (Kyron Laboratories (Pty) Ltd., Johannesburg, South Africa); carbon dioxide, helium and nitrogen (all from Afrox Ltd, Epping, South Africa); concentrated hydrochloric acid, methanol, and acetone (all analar grade; KIMIX Chemicals \& laboratory suppliers, USA); acetonitrile (HPLC grade, ACS specifications, Allied Signal Inc.); and formaldehyde and ethyl acetate (AR Saarchem Merck Chemicals (PTY) LTD), were used in the preparation of the plant materials, the assay of the plant materials, lung and perfusate samples and the isolated perfused lung experiments.

\subsection{Preparation of Artemisia afra extracts}

Artemisia afra was obtained from Montague museum (Montague, South Africa) and identified by Riaan Cedras at the herbarium at UWC (voucher specimen 6735). Fresh leaves were dried at $301 \mathrm{C}$ for $72 \mathrm{~h}$ in a well-ventilated oven until a constant weight, and ground to a fine powder. Aqueous extraction of $100 \mathrm{~g}$ of dried ground plant leaves with 1 L of boiling distilled water for 30 min was carried out, and the resultant infusion filtered, and freeze-dried to produce a dry flaky brownish extract. The resultant aqueous extract was stored in a desiccator in sealed amber bottles until further use.

\subsection{HPLC assay for the determination of luteolin levels}

The HPLC assays used in the study were all validated for separation and specificity, inter- and intra-day variability, recov- ery, linearity and lowest limit of detection. HPLC assays of un- hydrolyzed and hydrolyzed dried leaves and aqueous extract were carried out to quantify luteolin (aglycone and glycoside) levels in Artemisia afra. To prepare unhydrolyzed Artemisia afra for HPLC assay, $25 \mathrm{mg}$ of the aqueous extract and $100 \mathrm{mg}$ of the dried leaves were dissolved in $300 \mathrm{ml}$ and $1 \mathrm{ml}$ of distilled water respectively. The internal standard, Morin $(100 \mathrm{ml})$ was added to each sample, the contents thoroughly vortex-mixed for $1 \mathrm{~min}$, and thereafter extracted with $5 \mathrm{ml}$ ethyl-acetate. To produce hydrolyzed samples $4 \mathrm{ml}$ of $2 \mathrm{~N} \mathrm{HCl}$ was added to the vortexed mixture and heated in a water-bath at $801 \mathrm{C}$ for $40 \mathrm{~min}$, cooled to room temperature, and extracted with $5 \mathrm{ml}$ of ethyl-acetate. The ethyl-acetate extracts were evaporated to dryness under a gentle stream of nitrogen gas, the residue re-dissolved into $500 \mathrm{ml}$ of the mobile phase and $100 \mathrm{ml}$ of the solution run on a Beckman System Gold HPLC system (32-Karat ${ }^{\mathrm{TM}}$ software package) consisting of a programmable binary gradient pump (Beckman Gold Module 126 series), an auto sampler (Beckman Gold Module 507 series) with a diode array detector (Beckman Gold Module 168 series) (all Beckman, USA) and a Luna ${ }^{\mathrm{S}} \mathrm{C}-18$ reverse phase column (Phenomenex, USA). Eluting solvent was a mixture of acetonitrile and phosphate buffer (100 mM, pH 2) (3:7) pumped isocratically at a flow rate of $1 \mathrm{ml} / \mathrm{min}$. The luteolin peaks were detected at the wavelength of $349 \mathrm{~nm}$. 


\subsection{The isolated perfused lung system}

Male Wistar rats (300-400 g) obtained from the University of Cape Town (UCT) and the Medical Research Council (MRC), South Africa were used in this study. The animals were kept on a 12-h light/12-h darkness cycle in a well-ventilated animal room and allowed free access to food and water. All animal experiments were conducted in accordance with the internationally accepted principles for laboratory animal use and care, and the protocol as approved by the ethics committees of the MRC and University of the Western Cape (UWC).

A modified version of the isolated perfused lung (IPL) system as described by Uhlig and Taylor (1998) was used to determine the effects of Artemisia afra steam inhalation, nebulized luteolin, and nebulized aqueous leaf extract on lung function, as well as the pulmonary disposition of intravenous administered luteolin. In this system, the jacketed organ chamber was fitted with a pneumotachometer to measure air flow rate, while the lungs were perfused via a pulmonary arterial cannula connected to a peristal- tic pump, and discharged via a pulmonary venous cannula. A bubble trap in the pulmonary arterial cannula allowed for the bolus administration of drugs and also contained a pressure transducer used for the continuous measurement of pulmonary arterial pressure (PAP). The lung chamber was also linked to a chamber pressure transducer for measuring trans-pulmonary pressure (chamber pressure). Ventilation of the lung was achieved by a ventilation control module (VCM) connected to the trachea via a tube containing a change-over valve that allowed for the switch of ventilation between negative and positive pressure ventilation. The respiratory rate and the level of the end- expiratory and end-aspiratory pressures were controlled by the VCM settings while the frequency of deep breaths ("sighs") was adjusted through the timer counter module (TCM).

Male Wistar rats (300-400 g) were anaesthetized with sodium pentobarbitone (100 $\mathrm{mg} / \mathrm{kg}$; IP), tracheotomised with a cannula and ventilation at positive pressures of about $10 \mathrm{~cm} \mathrm{H}_{2} \mathrm{O}$ and 80 breaths/min started. The animal was then exsanguinated, and the upper abdomen and thorax dissected to expose the lungs. The right ventricle was cannulated with an arterial cannula, while the left atrium was cannulated with a venous cannula. Perfusion with the perfusion fluid was then initiated at $5 \mathrm{ml} / \mathrm{min}$ while the lungs were dissected free of the animal and placed in the artificial thorax chamber (Uhlig and Wollin, 1994). Positive pressure ventilation was then stopped and lungs switched to negative pressure ventilation with the pressure in the chamber fluctuating between an end-inspiratory pressure of -10 to $-16 \mathrm{~cm} \mathrm{H}_{2} \mathrm{O}$ and end- expiratory pressure of -2 $\mathrm{cm} \mathrm{H}_{2} \mathrm{O}$. Perfusion flow rate was also increased to $25 \mathrm{ml} / \mathrm{min}$ and a pneumotachometer connected to the external input module (EIM) via a differential pressure transducer

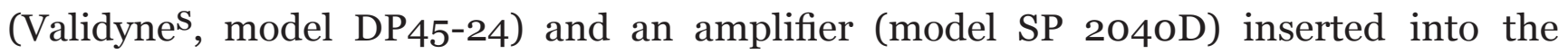
organ chamber to measure the airflow rate. Perfusion fluid (Krebs-Henseleit buffer containing calcium chloride $2.5 \mathrm{mM}$, Magnesium sulfate $1.2 \mathrm{mM}$, sodium chloride 118 
$\mathrm{mM}$, potassium chloride $4.7 \mathrm{mM}$, potassium dihydrogen phosphate $1.2 \mathrm{mM}, 2 \%$ bovine serum albumin (BSA), and $0.1 \%$ glucose; $\mathrm{pH} 7.3-7.4$ ) was pumped through the lung vasculature using single pass perfusion for $5 \mathrm{~min}$ to clear the organ debris before changing to recirculation mode for the rest of the experiment to mimic the normal body circulation. Lungs were allowed to equilibrate and stabilize for $20 \mathrm{~min}$ before treatment with test compounds. At the end of each experiment, the lungs were assessed for edema formation, and separated from the trachea and the heart before being weighed on an electronic balance. During experi- ments tidal volume, mean pulmonary pressure, airflow rate and trans-pulmonary pressure were continuously monitored via the PLUGSYS $^{\mathrm{TM}}$ system on a computer. Lung resistance (LR) and compliance (LC) values were determined automatically from air- flow rates and pulmonary pressure readings by the PULMODYN $^{\mathrm{TM}}$ computer software. In order to determine the viability of the model, lungs were perfused with perfusate for $2 \mathrm{~h}$ and were found to be stable with the following values for pulmonary parameters at the start and end of perfusion: tidal volume (4.3670.163.4870.91); lung resistance (0.5270.07-0.6170.05) and lung compliance (0.6470.57$0.5870 .17)$.

\subsection{Effects of traditionally prepared Artemisia afra steam inhalation on lung function}

To determine the effects of traditionally prepared Artemisia afra steam inhalation on lung function, dried leaves of Artemisia afra were boiled for 5 min and the resulting steam introduced into the IPL system via 3 cooling and condensation chambers with com- pressed air used to drive the stream of the resultant vapor in the direction of the organ chamber. The lungs were allowed to inhale the steam for 3 min under negative ventilation and thereafter lung function monitored for $30 \mathrm{~min}$. A second outlet of the steam- feeder was immersed in $1 \mathrm{ml}$ of distilled water during steam inhalation to trap aerosolized compounds and the sample sub- jected to HPLC analysis to identify and quantify the amount of luteolin aerosolised during the steam inhalation period. Control lungs received $3 \mathrm{~min}$ of inhaled steam from $100 \mathrm{ml}$ saline, while test lungs received steam from either $10 \mathrm{mg} / \mathrm{ml}(1 \mathrm{~g}$ in $100 \mathrm{ml}$ saline $)$ or $50 \mathrm{mg} / \mathrm{ml}(5 \mathrm{~g}$ in $100 \mathrm{ml}$ saline) Artemisia afra.

\subsection{Effects of nebulized luteolin and aqueous Artemisia afra extract on lung function}

To determine the effects of nebulized luteolin and the aqueous extract of Artemisia afra on lung function, a jet nebulizer used to generate the aerosol was linked via a thin silicone tube to the thorax chamber. The lungs were nebulized for 3 min under negative ventilation either with $4 \mathrm{ml}$ of saline (control), $4 \mathrm{ml}$ saline containing $250 \mathrm{mg}$ luteolin per $1 \mathrm{ml}$ of saline or $4 \mathrm{ml}$ saline containing $100 \mathrm{mg}$ Artemisia afra aqueous extract per $1 \mathrm{ml}$ of saline (equivalent to $250 \mathrm{mg}$ luteolin per $\mathrm{ml}$ of saline). Lung function was monitored thereafter for 30 min. During nebulisa- tion, a second outlet of the nebulizer feeder was immersed in $1 \mathrm{ml}$ of distilled water to trap aerosolized compounds, and the sample analyzed with HPLC to identify and quantify the amount of luteolin trapped during the nebulization period. 


\subsection{Disposition and effect of IV administered luteolin in IPL}

To determine the effect and disposition of luteolin in the lungs, the following procedure was followed. Lungs were perfused with a perfusion solution containing either $2 \mathrm{mg} / \mathrm{ml}$ or $10 \mathrm{mg} / \mathrm{ml}$ of luteo- lin for $90 \mathrm{~min}$. During luteolin perfusion, $1 \mathrm{ml}$ samples of perfusate were collected at $3,510,15,30,45,60,75$ and $90 \mathrm{~min}$ and stored at $21 \mathrm{C}$ for later analysis. Perfusate samples were then divided into $2 \times 500 \mathrm{ml}$ samples to assay for luteolin in hydrolyzed and un- hydrolyzed samples. Each $500 \mathrm{ml}$ perfusate was spiked with $10 \mathrm{mg}$ morin (internal standard), vortex-mixed and then $1 \mathrm{ml}$ methanol added to precipitate proteins. Un-hydrolyzed samples were then directly extracted with $5 \mathrm{ml}$ of ethyl-acetate, while for hydrolyzed samples, $2 \mathrm{ml}$ of $2 \mathrm{~N}$ HCL was added to each sample, heated in a water bath at $801 \mathrm{C}$ for $40 \mathrm{~min}$, cooled to room temperature, and extracted with $5 \mathrm{ml}$ of ethyl acetate. Ethyl acetate extracts were evaporated to dryness under a stream of nitrogen gas, the residue re-dissolved into $500 \mathrm{ml}$ of HPLC mobile phase, and $100 \mathrm{ml}$ of the solution injected into HPLC column for analysis.

\subsection{Data analysis}

To determine the changes in lung mechanics after treatment with the different plant compounds, the following parameters were observed: tidal volume (TV), lung compliance (LC) and resistance (LR) (calculated using the PULMODYN Software). Mean values ( $n^{1 / 4} 5$ ) at each specified time interval was calculated and two-way ANOVA analysis followed by the Bonferroni post test or $t$ - test analysis used to determine the statistical significance. To determine the levels of luteolin in the plant extracts and the effluent perfusate, luteolin and morin peak heights were obtained from the HPLC 32-Karat software package generated data, and the luteolin to morin peak height ratios calculated using Excel. The concentration vs. ratios data were then subjected to linear regres- sion analysis, and used for construction of the standard curve and luteolin concentrations determined from the same standard curve using Graphpads Prism software.

\section{Results}

\subsection{Identification and quantification of luteolin in the plant material}

The developed HPLC assay was fairly robust, linear over the concentration range of 5-30 $\mathrm{mg}$ of luteolin/ml solution with a correlation coefficient $\left(r^{2}\right)$ of 0.9916 . The assay had high assay reproducibility (i.e. CV below 3\%), was quite sensitive with a LLQ of 70 ng on column, and therefore deemed suitable for the study. Hydrolyzed and un-hydrolyzed forms of the aqueous extract and dried leaves of Artemisia afra were analyzed by HPLC assay. Each extract produced distinct peaks for luteolin with a retention time of $14.4370 .298 \mathrm{~min}$, which were easily quantifiable (Fig. 1 and Table 1). Additional peaks with much shorter retention times than luteolin and morin (internal standard) were evident in the chromatograms, with the peaks from the solutions of the hydro- lyzed extract being more prominent than that of the hydrolyzed leaves (Table 1). 
3.2 Effect of Artemisia afra steam inhalation, nebulized freeze-dried Artemisia afra aqueous extract and nebulized luteolin on lung mechanics 3.2.1 Effect on tidal volume

Steam inhalation from $1 \mathrm{~g}$ and $5 \mathrm{~g}$ quantities (10 $\mathrm{mg} / \mathrm{ml}$ and $50 \mathrm{mg} / \mathrm{ml}$ ) of the dry leaves of Artemisia afra boiled in 100ml of normal saline led to no statistically significant initial changes in tidal volume (TV) post exposure-3.6\% (from $4.1970 .129 \mathrm{ml}$ to 4.3470 .140 $\mathrm{ml}$ ) and $7.6 \%$ (from $4.2270 .120 \mathrm{ml}$ to $4.5470 .088 \mathrm{ml}$ ) respectively (Fig. 2).

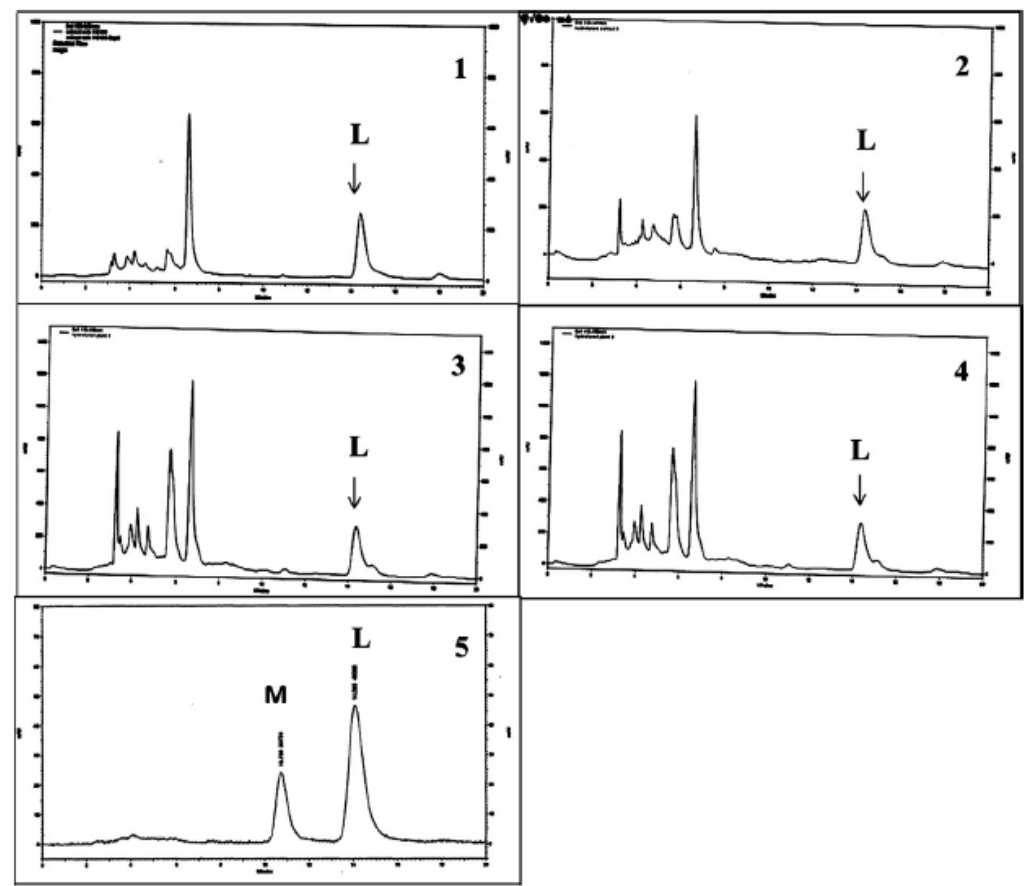

Fig. 1. Representative HPLC chromatograms of; un-hydrolyzed Artemisia afra leaves (1); hydrolyzed Artemisia afra leaves (2); un-hydrolyzed Artemisia afra aqueous extract (3); hydrolyzed Artemisia afra aqueous extract (4); and pure Luteolin (L) with internal standard Morin (M) (5).

Table 1

Hydrolyzed and un-hydrolyzed luteolin concentrations ( $\mu \mathrm{g} / 25 \mathrm{mg}$ of extract) in aqueous and dried leaf extracts of Artemisia afra, $n=5$.

\begin{tabular}{ll}
\hline Artemisia afra material preparation & $\begin{array}{l}\text { Luteolin concentration } \\
(\mu \mathrm{g} / \mathbf{2 5} \mathbf{~ m g}) \pm \text { SEM }\end{array}$ \\
\hline Hydrolyzed aqueous extract & $49.55 \pm 0.402$ \\
Un-hydrolyzed aqueous extract & $25.82 \pm \pm 0.129$ \\
Hydrolyzed dried leaves & $15.94 \pm 1.183$ \\
Un-hydrolyzed dried leaves & $12.42 \pm 0.257$ \\
\hline
\end{tabular}

This was however followed by a decrease at a steady rate of $0.014470 .0042 \mathrm{ml} / \mathrm{min}$ for 10 $\mathrm{mg} / \mathrm{ml}$, while the increase in TV from the $50 \mathrm{mg} / \mathrm{ml}$ dose was sustained for $16 \mathrm{~min}$ before decreasing at a steady rate similar to that of the $10 \mathrm{mg} / \mathrm{ml}$ and saline group of lungs. Nebulizing the lungs with luteolin $(250 \mathrm{ug} / \mathrm{ml})$ led to a statistically significant (11\%) increase in TV (from 3.8670.078 ml to $4.2570 .189 \mathrm{ml}$ ) which was sustained for the duration of the post-nebulization period (Fig. 2). Nebulizing with Artemisia afra aqueous extract also led to a statistically significant (18\%) increase in TV, which was greater than that produced by all other drugs, and sustained throughout the monitoring period (Fig. 2). 
Perfusion with luteolin ( $2 \mathrm{mg} / \mathrm{ml}$ and $10 \mathrm{mg} / \mathrm{ml}$ ) led to no statistically significant initial changes in TV ( $5.6 \%$ and $13.7 \%$ decreases respectively). However, post-perfusion rate of decrease was statistically significantly less than the pre-treatment rate for both doses indicating that luteolin administered into the perfusion media stabilized the tidal volume (Fig. 2).

\subsubsection{Effect on lung compliance}

Steam inhalation of Artemisia afra leaves led to statistically significant dosedependent increases in lung compliance (LC), with the $10 \mathrm{mg} / \mathrm{ml}$ and $50 \mathrm{mg} / \mathrm{ml}$ doses increasing $\mathrm{LC}$ by $3.4 \%$ (from $0.6270 .022 \mathrm{ml} / \mathrm{cm} \mathrm{H}_{2} \mathrm{O}$ to $0.6470 .019 \mathrm{ml} / \mathrm{cm} \mathrm{H}_{2} \mathrm{O}$ ) and $11.8 \%$ (from $0.5970 .026 \mathrm{ml} / \mathrm{cm} \mathrm{H}_{2} \mathrm{O}$ to $0.6670 .027 \mathrm{ml} / \mathrm{cm} \mathrm{H}_{2} \mathrm{O}$ ) respectively (Fig. 3). Increase in LC with the lower dose was sustained for only $20 \mathrm{~min}$, while the increase from the higher dose was sustained throughout the experimental period.

Nebulizing the lungs with luteolin $(250 \mathrm{ug} / \mathrm{ml}$ ) led to a statistically significant $36.4 \%$ increase in $\mathrm{LC}$ (from $0.6570 .012 \mathrm{ml} / \mathrm{cm} \mathrm{H}_{2} \mathrm{O}$ to $0.8870 .019 \mathrm{ml} / \mathrm{cm} \mathrm{H}_{2} \mathrm{O}$ ) (Fig. 3). This improvement was sustained for the entire post nebulization monitoring period. When the lungs were however nebulized with Artemisia afra extract equivalent to $250 \mathrm{ug} / \mathrm{ml}$ of luteolin, LC improved by $43.4 \%$ (from $0.7070 .029 \mathrm{ml} / \mathrm{cm} \mathrm{H}_{2} \mathrm{O}$ to $1.0070 .043 \mathrm{ml} / \mathrm{cm}$ $\mathrm{H}_{2} \mathrm{O}$ ), and only exhibited a slight decline during the monitoring period (Fig. 3). Intravenous perfusion with luteolin $(2 \mathrm{mg} / \mathrm{ml})$ produced an initial non-statistically significant (1\%) change in LC (from $0.5170 .039 \mathrm{ml} / \mathrm{cm} \mathrm{H}_{2} \mathrm{O}$ to $0.5170 .047 \mathrm{ml} / \mathrm{cm} \mathrm{H}_{2} \mathrm{O}$ ) (Fig. 3). Lung compliance however increased at a steady rate $(0.0055870 .00289 \mathrm{ml} / \mathrm{cm}$ $\mathrm{H}_{2} \mathrm{O} / \mathrm{min}$ ) throughout the posttreatment period leading to a peak value (1.0270.093 $\mathrm{ml} / \mathrm{cm} \mathrm{H}_{2} \mathrm{O}$ ) representing a statistically significant $98.5 \%$ increase. The higher luteolin (10 $\mathrm{mg} / \mathrm{ml}$ ) dose also produced an initial non-statistically significant (1.9\%) change in LC (from $0.5470 .034 \mathrm{ml} / \mathrm{cm} \mathrm{H}_{2} \mathrm{O}$ to $0.5570 .039 \mathrm{ml} / \mathrm{cm} \mathrm{H}_{2} \mathrm{O}$ ), also followed by a steady rate (0.0072170.00113 $\mathrm{ml} / \mathrm{cm} \mathrm{H}_{2} \mathrm{O} / \mathrm{min}$ ) increase over the post treatment period to a statistically significant higher final value of $1.1770 .028 \mathrm{ml} / \mathrm{cm} \mathrm{H}_{2} \mathrm{O}$ (Fig. 3).

\subsubsection{Effect on lung resistance}

Steam inhalation with and $50 \mathrm{mg} / \mathrm{ml}$ Artemisia afra leaves extract led to an initial statistically significant decreases in lung resistance (LR) (9.7\% and $11 \%$ respectively). This was however followed by an increases at steady rates similar to and slightly higher than the pre-inhalation rate for the $10 \mathrm{mg} / \mathrm{ml}$ (0.0031170.00148 $\mathrm{cm} \mathrm{H}_{2} \mathrm{O} \mathrm{s} / \mathrm{ml} / \mathrm{min}$ ) and $50 \mathrm{mg} / \mathrm{ml}$ (0.0058470.00096 $\mathrm{cm} \mathrm{H} \mathrm{H}_{2} \mathrm{O} \mathrm{s} / \mathrm{ml} / \mathrm{min}$ ) doses respectively (Fig. 4). 

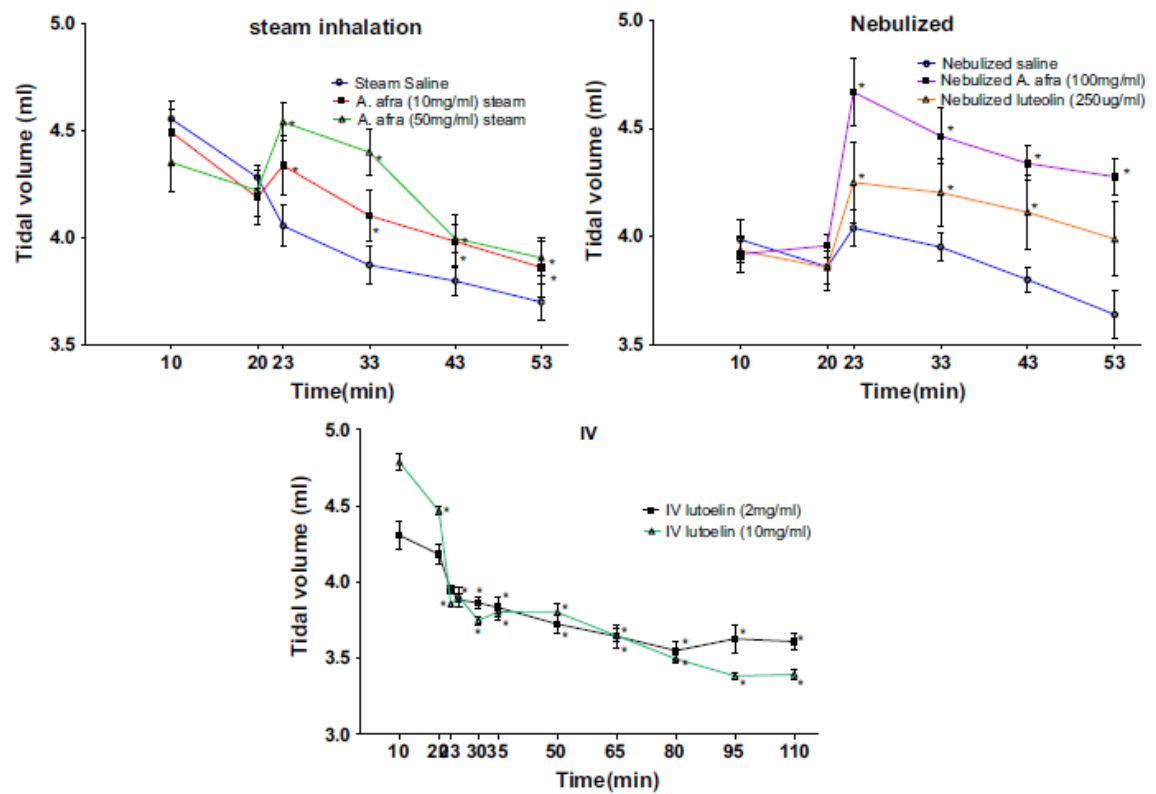

Fig. 2. Effect of Artemisia afra steam inhalation, nebulized freeze-dried Artemisia afra aqueous extract and nebulized luteolin on tidal volume (TV) in isolated perfused rat lungs. * Indicates statistical significance $(p<0.05)$ when compared to baseline at $10 \mathrm{~min}, n=5$.
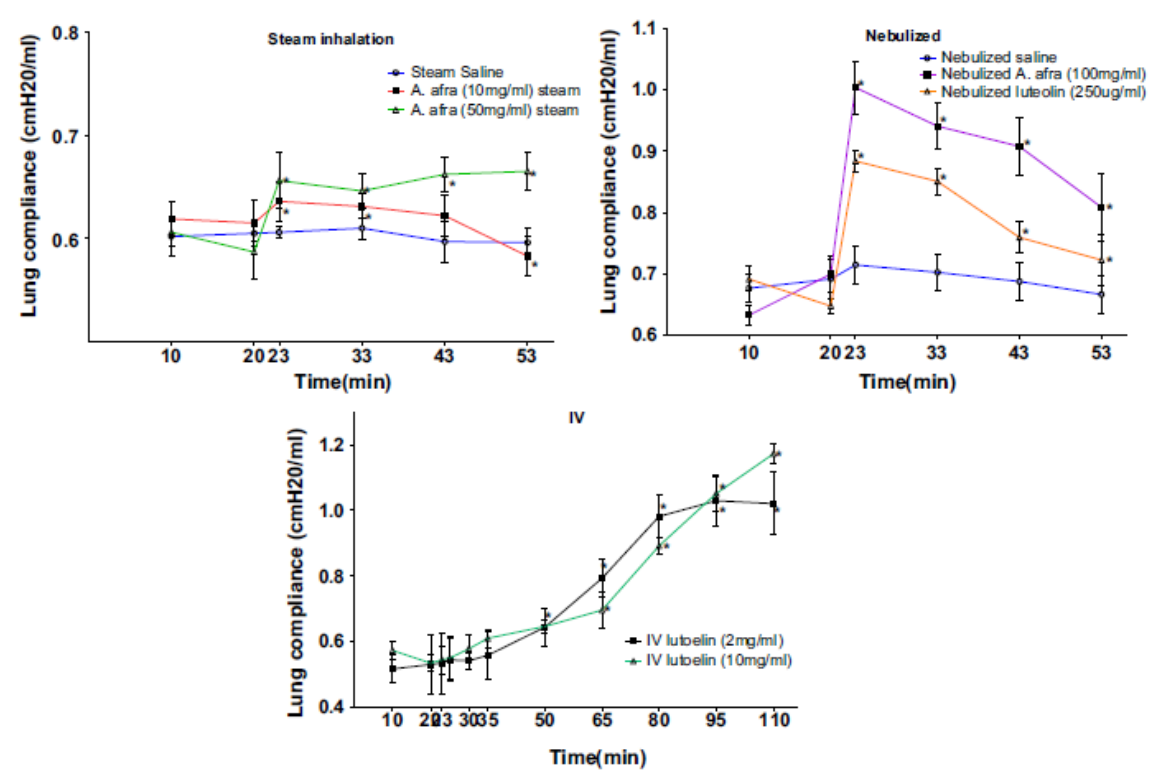

Fig. 3. Effect of Artemisia afra steam inhalation, nebulized freeze-dried Artemisia afra aqueous extract and nebulized luteolin on lung compliance (LC) in isolated perfused rat lungs. * Indicates statistical significance $(p<0.05)$ when compared to baseline at $10 \mathrm{~min}, n=5$.

Nebulizing the lungs with luteolin $(250 \mathrm{ug} / \mathrm{ml})$ led to an initial statistically significant $19.7 \%$ decrease in $\mathrm{LR}$ (from $0.6670 .014 \mathrm{~cm} \mathrm{H}_{2} \mathrm{O} \mathrm{s} / \mathrm{ml}$ to $0.5370 .014 \mathrm{~cm} \mathrm{H}_{2} \mathrm{O} \mathrm{s} / \mathrm{ml}$ ), followed by an increase at a steady rate $\left(0.0057470 .0009 \mathrm{~cm} \mathrm{H}{ }_{2} \mathrm{O} . \mathrm{s} / \mathrm{ml} / \mathrm{min}\right)$ similar to the post-nebulization rate of increase in the saline group. Artemisia afra extract nebulisation on the other hand also led to a statistically significant though smaller decrease in LR (by 8.5\%; from $0.6370 .013 \mathrm{~cm} \mathrm{H}_{2} \mathrm{O} \mathrm{s} / \mathrm{ml}$ to $0.5770 .038 \mathrm{~cm} \mathrm{H}_{2} \mathrm{O}$ $\mathrm{s} / \mathrm{ml}$ ). This decrease unlike that produced by luteolin was sustained throughout the post-nebulization period (Fig. 4). 
Intravenous perfusion with luteolin $(2 \mathrm{mg} / \mathrm{ml})$ led to an initial non-statistically significant change in LR (from $0.5670 .065 \mathrm{~cm} \mathrm{H} \mathrm{H}_{2} \mathrm{O} \mathrm{s} / \mathrm{ml}$ to $0.5570 .065 \mathrm{~cm} \mathrm{H} \mathrm{H}_{2} \mathrm{O} \mathrm{s} / \mathrm{ml}$ ), with a further decrease (to $0.4170 .077 \mathrm{~cm} \mathrm{H}_{2} \mathrm{O} \mathrm{s} / \mathrm{ml}$ ) occurring after 10 min post-perfusion followed by an increase (to $0.4970 .044 \mathrm{~cm} \mathrm{H}_{2} \mathrm{O} \mathrm{s} / \mathrm{ml}$ ) after $25 \mathrm{~min}$, and then a gradual decline followed by a slight increase towards the end of the monitoring period to levels which were statistically significantly lower than the pre-treatment levels. The higher luteolin dose $(10 \mathrm{mg} / \mathrm{ml}$ ) induced an initial statistically significant increase in LR (from 0.4170.052 $\mathrm{cm} \mathrm{H}_{2} \mathrm{O} \mathrm{s} / \mathrm{ml}$ to $0.5770 .063 \mathrm{~cm} \mathrm{H}_{2} \mathrm{O} \mathrm{s} / \mathrm{ml}$ ), followed by a brief, sharp drop to $0.406070 .07716 \mathrm{~cm} \mathrm{H}_{2} \mathrm{O} \mathrm{s} / \mathrm{ml}$ after $10 \mathrm{~min}$, then a subsequent steady increase in levels over $35 \mathrm{~min}$, and finally a gradual decrease to values that remained significantly higher than the pre-treatment LR levels at the end of the post treatment period (Fig. 4).

\subsection{The disposition profile of intravenously administered luteolin in the IPL}

Analysis of luteolin levels in lung perfusion medium indicated that pre-perfusion the 2 $\mathrm{mg} / \mathrm{ml}$ luteolin perfusate contained $1.9670 .0143 \mathrm{mg} / \mathrm{ml}$ free (un-hydrolyzed luteolin), while a comparable $1.9870 .0074 \mathrm{mg} / \mathrm{ml}$ was obtained after acid hydrolysis. For the higher dose $(10 \mathrm{mg} / \mathrm{ml})$, free luteolin was $9.8670 .0933 \mathrm{mg} / \mathrm{ml}$ and aglycone luteolin level was $9.8770 .0098 \mathrm{mg} / \mathrm{ml}$, confirming that no alteration in luteolin levels occurred in the albumin containing perfusion medium.

Levels of free luteolin in the lung perfusate first increased slightly, then decreased at a rapid rate $(0.1870 .002086 \mathrm{mg} / \mathrm{ml} / \mathrm{min})$ for about $30 \mathrm{~min}$, followed by a slower rate of decrease $(0.4970 .003674 \mathrm{mg} / \mathrm{ml} / \mathrm{min})$ to the end of the perfusion period. The first order rate constant and half-life for the terminal phase were $8.73 \times 10^{-} 3 \mathrm{~min}^{-1}$ and $79.381 \mathrm{~min}$, respectively. For the higher luteolin dose $(10 \mathrm{mg} / \mathrm{ml})$, the free luteolin perfusate levels first increased to $7.4070 .1647 \mathrm{mg} / \mathrm{ml}$, decreased at a steady rate (0.5970.0019 $\mathrm{mg} / \mathrm{ml} / \mathrm{min}$ ) for $5 \mathrm{~min}$ before increasing steadily (0.4270.01667 $\mathrm{mg} / \mathrm{ml} / \mathrm{min}$ ) until the end of the perfusion period. The first order rate constant and half-life for the terminal phase were $2.501 \times 10^{-4} \mathrm{~min}^{-1}$ and $2770.89 \mathrm{~min}$, respectively (Table 2).

\section{Discussion}

Traditionally prepared Artemisia afra aqueous extract contained higher content of luteolin than the freeze-dried extract, with approximately $50 \%$ of luteolin in acidhydrolyzable, presumably glycoside form. Higher concentrations of luteolin have been extracted from the plant and the lower concentrations isolated here is most likely due to the nature of the solvent used in the process (Muganga, 2004). The results confirmed the presence of quantifiable amounts luteolin in Artemisia afra extracts as previously reported by other researchers (Muganga, 2004; Waithaka, 2004), indicating the possibility that luteolin may be implicated in any effect the extracts have on the lungs. 

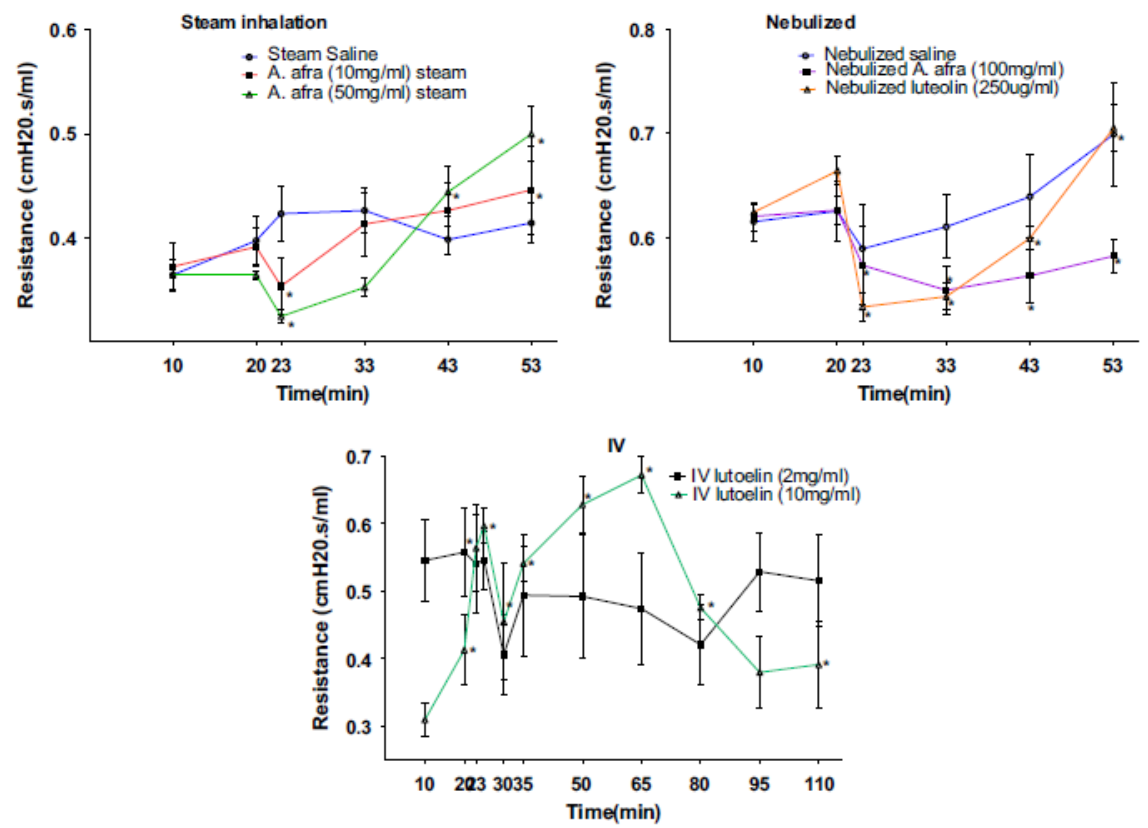

Fig. 4. Effect of Artemisia afra steam inhalation, nebulized freeze-dried Artemisia afra aqueous extract and nebulized luteolin on lung resistance (LR) in isolated perfused rat lungs. * Indicates statistical significance $(p<0.05)$ when compared to baseline at $10 \mathrm{~min}, n=5$.

\begin{tabular}{|c|c|c|c|c|c|c|}
\hline \multirow{2}{*}{$\begin{array}{l}\text { Time } \\
\text { (min) }\end{array}$} & \multicolumn{3}{|l|}{$2 \mu \mathrm{g} / \mathrm{ml}$ luteolin } & \multicolumn{3}{|l|}{$10 \mu \mathrm{g} / \mathrm{ml}$ luteolin } \\
\hline & $\begin{array}{l}\text { Free (aglycone) } \\
\text { luteolin }(\mu \mathrm{g} / \mathrm{ml}) \\
\text { mean } \pm \text { SEM }\end{array}$ & $\begin{array}{l}\text { Conjugated } \\
\text { luteolin }(\mu \mathrm{g} / \mathrm{ml}) \\
\text { mean } \pm \mathrm{SEM}\end{array}$ & $\begin{array}{l}\text { Total luteolin }(\mu \mathrm{g} / \mathrm{ml}) \\
\text { (free+conjugated) } \\
\text { mean } \pm \text { SEM }\end{array}$ & $\begin{array}{l}\text { Free levels }(\mu \mathrm{g} / \mathrm{ml}) \\
\text { (aglycone) } \\
\text { mean } \pm \text { SEM }\end{array}$ & $\begin{array}{l}\text { Conjugated }(\mu \mathrm{g} / \mathrm{ml}) \\
\text { (total-free) } \\
\text { mean } \pm \text { SEM }\end{array}$ & $\begin{array}{l}\text { Total levels }(\mu \mathrm{g} / \mathrm{ml}) \\
(\text { free }+ \text { conjugated) } \\
\text { mean } \pm \text { SEM }\end{array}$ \\
\hline 0 & $0.00 \pm 0.000$ & $0.00 \pm 0.000$ & $0.00 \pm 0.000$ & $0.00 \pm 0.000$ & $0.00 \pm 0.000$ & $0.00 \pm 0.000$ \\
\hline 3 & $1.10 \pm 0.146$ & $0.37 \pm 0.106$ & $1.47 \pm 0.172$ & $7.34 \pm 0.167$ & $0.88 \pm 0.260$ & $8.22 \pm 0.116$ \\
\hline 5 & $1.18 \pm 0.046$ & $0.46 \pm 0.067$ & $1.65 \pm 0.042$ & $7.40 \pm 0.165$ & $0.93 \pm 0.460$ & $8.33 \pm 0.266$ \\
\hline 10 & $0.91 \pm 0.122$ & $0.66 \pm 0.163$ & $1.57 \pm 0.026$ & $7.23 \pm 0.165$ & $1.00 \pm 0.463$ & $8.22 \pm 0.271$ \\
\hline 15 & $0.88 \pm 0.091$ & $0.43 \pm 0.138$ & $1.31 \pm 0.118$ & $6.60 \pm 0.224$ & $1.01 \pm 0.458$ & $7.61 \pm 0.173$ \\
\hline 30 & $0.70 \pm 0.051$ & $0.28 \pm 0.133$ & $0.98 \pm 0.080$ & $6.81 \pm 0.129$ & $1.01 \pm 0.377$ & $7.82 \pm 0.268$ \\
\hline 45 & $0.65 \pm 0.055$ & $0.33 \pm 0.105$ & $0.99 \pm 0.069$ & $6.66 \pm 0.327$ & $1.09 \pm 0.524$ & $7.76 \pm 0.264$ \\
\hline 60 & $0.57 \pm 0.032$ & $0.31 \pm 0.112$ & $0.88 \pm 0.082$ & $6.84 \pm 0.263$ & $0.99 \pm 0.350$ & $7.83 \pm 0.264$ \\
\hline 75 & $0.58 \pm 0.042$ & $0.20 \pm 0.078$ & $0.78 \pm 0.070$ & $6.98 \pm 0.220$ & $0.85 \pm 0.474$ & $7.83 \pm 0.404$ \\
\hline 90 & $0.52 \pm 0.051$ & $0.26 \pm 0.091$ & $0.78 \pm 0.578$ & $7.23 \pm 0.189$ & $0.98 \pm 0.460$ & $8.21 \pm 0.346$ \\
\hline
\end{tabular}

For this study the IPL was a particularly useful and novel tool to evaluate both the pulmonary effect of, and the pulmonary availability of an active constituent (luteolin) in Artemisia afra, as it would be administered traditionally, i.e. in steam inhalation form. Moreover changes in the pulmonary parameters such as TV, LR and LC are particularly appropriate and sensitive indicators of anti-asthmatic activity. Tidal volume is the volume of gas inspired or expired during each respiratory cycle. It usually decreases during bronchoconstriction and increases during bronchodilation, and is often affected during pulmonary disorders such as asthma and COPD (Ruppel, 2004). Compliance is the volume change per unit of pressure change for lungs and is measured in millimeters per centimeter of water $\left(\mathrm{ml} / \mathrm{cm} \mathrm{H}_{2} \mathrm{O}\right.$ ) (Ruppel, 2004). CL is an index of functional stiffness of the lung and reflects changes to small airways, thus making compliance a useful test to indicate changes in periphery of the lung (Drazen, 1984). It is normally decreased in pulmonary edema or congestion, atelectasis, pneumonia and restrictive diseases such as pulmonary fibrosis and asthma. Known bronchodilators 
usually increase the lung compliance (Ruppel, 2004). Finally, airway resistance (RL) is defined as the pressure difference required for a unit flow change and is usually measured in centimeters of water per milliliter per second. It is the measurement of clinical and physiological interest, and is useful for evaluating the respiratory effects of bronchodilatory or bronchoconstrictive drugs. Increased resistance is usually due to narrowing and collapse of airways and clinically related to an assortment of respiratory diseases such as asthma and bronchitis (Lausted and Johnson, 1999; Ruppel, 2004).

Steam inhalation of Artemisia afra induced dose-dependent increases in TV and LC, while leading to decreases in LR. These effects were similar to those obtained with known bronchodilators suggesting that the plant contained compounds with bronchodilatory activity (Svens and Rvrfeldt, 2001). Since luteolin a flavonoid found in Artemisia afra and previously associated with bronchodilatory activities (Das et al., 2003) was found in significant quantities in the extract, it probably played a role in the observed effects of the steam inhalation. Flavonoids have been reported to trigger the release of pulmonary surfactants which in turn reduce the surface tension in the lung tissues, thus reducing airway resistance, while also increasing the elasticity of the lung and hence LC (Niemeier, 1984). Lung compliance was increased in particular possibly via a variety of factors, including increased lung elasticity, smooth muscle relaxation or improved activity of the pulmonary surfactant (Niemeier, 1984). Improved activity of the pulmonary surfactant due to other constituents of the extract may in particular explain the better effect obtained with the extract than with luteolin. However HPLC analysis of the post-lung condensate from the extract did not detect luteolin. This suggests that either luteolin levels were below the limit of detection or that the bronchodilator effects were due to other compounds such as volatile oils like thujone (Roberts, 1990).

Nebulized luteolin also exhibited a bronchodilatory effect, with dose-dependent improvements in lung function (increased TV, LC and decreased LR) greater than those obtained with the steam inhalation Artemisia afra. This ordinarily would have suggested that luteolin was responsible for the bronchodilatory effects of the plant, except that the nebulized Artemisia afra extract produced even greater improvements in lung function. Nebulized Artemisia afra also sustained the improved lung function better than Artemisia afra steam inhalation or nebulized luteolin despite containing luteolin equivalent in dose to the nebulized luteolin dose. The improvement in lung function with nebulized luteolin indicate that luteolin does play a role in Artemisia afra effect, but improved effect with the nebulized extract suggests the presence of either other active constituents (possibly flavonoids such as quercetin) or complimentary compounds in the plant. There is also the possibility of improved bioavailability of luteolin from the plant extract possibly due to surfactant effect from other contained flavonoids. Higher luteolin yields in post-lung condensate from nebulized plant extract than from luteolin correlates with studies showing a better release and greater bioavailability of luteolin when contained in plant material than its aglycone form suggesting that the improved efficacy was due to the improved 
bioavailability of the extract (Markam, 1982; Muganga, 2004). Once more despite the evidence of the effect of luteolin on lung function, luteolin was not detected in the perfusate after the inhalation of the nebulized luteolin or Artemisia afra aqueous extract solutions. It may be that luteolin levels in the perfusate were below the lower limit of detection of the HPLC assay used in this study, or that the compound had a poor disposition in the lungs or was rapidly metabolized amongst other reasons (Tronde, 2002).

Luteolin was administered IV to study its disposition profile in the lungs at levels that produced comparably changes to lung dynamics as inhalation and nebulisation. Intravenously administered luteolin improved lung function similar to the effects obtained with steam inhalation and nebulisation, further confirming its bronchodilatory effect. A direct correlation between an increase in LC and a decrease in perfusate luteolin levels (indicative of luteolin uptake and/or metabolism) strongly suggests that the improved LC was due to luteolin activity. In fact, luteolin seems to particularly increase the lung compliance, an effect that might be caused by a variety of factors, including increased lung elasticity, smooth muscle relaxation or improved activity of the pulmonary surfactant (Niemeier, 1984). Further studies comparing the luteolin perfusate levels and its lung effects must however, be done before one can truly confirm such hypothesis. Nevertheless, this study strongly suggests that luteolin could be a worthy marker to monitor, establish and quantitate the pulmonary effects of Artemisia afra.

Nebulization produced better and more sustainable pulmonary effects than steam inhalation. There may be a variety of reasons for this, including that nebulization provided better deposition of plant actives in the lung than the steam inhalation. The administration of nebulized Artemisia afra extract could thus be a better alternative to the traditionally-used steam inhalation for the treatment of respiratory conditions, provided that other factors (such as convenience, availability of nebulizer) are also considered and dealt with.

In conclusion, inhalation of Artemisia afra steam and nebulized Artemisia afra extract and luteolin and intravenously-administered luteolin produced improvements in lung function similar to that obtained with known bronchodilators (Svens and Rvrfeldt, 2001). Artemisia afra extracts containing appreciable amounts of luteolin produced pulmonary effects similar in magnitude to that of luteolin, suggesting that luteolin could be an important contributor to the pulmonary effects of Artemisia afra.

Though it was not the objective of this study to determine the mechanism of action of luteolin or Artemisia afra effect on the lungs, but it could be speculated that this would include smooth muscle relaxation, and improved surfactant activity (Das et al., 2003). While the above results clearly indicate that Artemisia afra improved lung function in a similar way to luteolin, and that luteolin could therefore, be associated 
with the pulmonary effects produced by Artemisia afra, the mechanism for this effect is yet to be established. 


\section{References}

Avula, B., Wang, Y.-H., Smillie, T.J., Mabusela, W., Vincent, L., Weitz, F., Khan, I.A., 2009. Quantitative determination of flavonoids by column highperformance liquid chromatography with mass spectrometry and ultraviolet absorption detection in Artemisia afra and comparative studies with various species of Artemisa plants. Journal of AOAC International 92, 633-644.

Das, M., Ram, A., Ghosh, B., 2003. Luteolin alleviates bronchoconstriction and airway hyper reactivity in ovalbumin sensitized mice. Inflammation Research 52, 101-106.

Drazen, J.M., 1984. Physiological basis and interpretation of indices of pulmonary mechanics. Environmental Health Perspectives 56, 3-9.

Harborne, J.B., Williams, C.A., 2000. Advances in flavonoid research since 1992. Journal of Phytochemistry 55, 481-504.

Harris, L., 2002. An evaluation of the bronchodilatory properties of Mentha longifolia and Artemisia afra. Dissertation for a Degree of Master's in Pharmacy at the University Of The Western Cape, Bellville.

Iwu, M.M., 1993. Handbook of African Medicinal Plants. CRC Press, Boca Raton.

Kraft, C., Jenett-Siems, K., Siems, K., Jakupovic, J., Mavi, S., Bienzle, U., Eich, E., 2003. In vitro antiplasmodial evaluation of medicinal plants from Zimbabwe. Phytotherapy Research 17, 123-128.

Lausted, C.G., Johnson, A., 1999. Respiratory resistance measurement by an airflow pertubation device. Physiologic Measurements 20, 21-35.

Lui, Z., Chan, K., Hua, Z., Jiang, Z., Wong, Y., Xu, H., Liang, L., 2005. Pharmacokinetics and tissue distribution of sinomenine in rats and its tissue binding activity in vitro. Journal of Life Sciences 77, 3197-3209.

Mander, J., Quinn, N.W., Mander, M., 1997. Trade in Wildlife Medicinals in South Africa. Investigational Report No. 157. Institute of Natural Resources. Pietermar itzburg, pp. 1-3.

Markam, K.R., 1982. Techniques of Flavonoid Identification. Academic press, London, New York, Paris, pp. 1-16.

Mayosi, B.M., Flisher, A.J., Lalloo, U.G., Sitas, F., Tollman, S.M., Bradshaw, D., 2009. The burden of non-communicable diseases in South Africa. The Lancet 374, 934-947.

Mjiqiza, S., 2006. Evaluation of the Pulmonary Effects of the Traditionally Prepared Artemisia afra Steam Inhalation and Nebulized Aqueous Extract and the Possible Involvement of Flavonoid Luteolin. Dissertation for a M. Pharmacy in Science at the School of Pharmacy, University Of The Western Cape, Bellville.

Muganga, R., 2004. Luteolin Levels in Selected Folkloric Preparations and the Bioavailability of Luteolin from Artemisia afra Aqueous Extract in the Vervet Monkey. Dissertation for a Degree of Master's in Pharmacy at the University Of The Western Cape, Bellville. 
Mukinda, J.T., Syce, J.A., Fisher, D., Meyer, M., 2010. Effect of the plant matrix on the uptake of luteolin derivative-containing Artemisia afra aqueous-extract in Caco-2 cells. Journal of Ethnopharmacology 130, 439-449.

Niemeier, R.W., 1984. The isolated perfused lung. Environmental Health Perspective 56, 35-41.

Roberts, M., 1990. Indigenous Healing Plants. Southern Book Publishers, Johannesburg, pp. 226-228.

Ruppel, G., 2004. Manual of Pulmonary Function Testing. Mosby, Missouri, pp. 1746.

Sanchez de Rojas, V.R., Ortega, T., Villar, A., 1995. Inhibitory effect of Cistus populifolius on contractile responses in the isolated rat duodenum. Journal of Ethnopharmacology 46, 59-62.

Scalbert, A., Williamson, G., 2000. Dietary intake and bioavailability of polyphenols in symposium: chocolate: modern science investigates an ancient medicine. Journal of Nutrition and Dietary Suppl. 130, 20732085.

Shimoi, K., Okada, H., Hara, Y., Hiroyo, Y., Kinae, N., Goda, T., Furugori, M., Takase, S., 1998. Intestinal absorption of luteolin $7-\mathrm{O}-\beta$-glucoside in rats and humans. FEBS Letters 438, 220-224.

Spencer, J.P.E., Chowrimooto, G., Choudhary, R., Debnam, E.S., Srai, S.K., Riceevans, C., 1999. The small intestine can both absorb and glucuronidate luminal flavonoids. FEBS Letters 468, 224-230.

Springfield, E.P., Eagles, P.K.F., Scott, G., 2005. Quality assessment of South African herbal medicines by means of HPLC fingerprinting. Journal of Ethnopharmacology 101, 75-83.

Svens, K., Rvrfeldt, A., 2001. A Study of Mechanisms Underlying AmitriptyllineInduced Acute Lung Function Impairment. Journal of Pharmacology and Toxicology 177, 179-187.

Tronde, A., 2002. In Vitro and In Vivo Investigations of Drug Absorption Across the Lung Barrier and Its Relation to Drug Physicochemical Properties. Dissertation for the Degree of Doctor of Philosophy in Biopharmaceutics at Uppsala University.

Uhlig, S., Taylor, A.E., 1998. Methods in Pulmonary Research. Deutsche Bibliothek Cataloging-in-Publication Data, Berlin, pp. 29-55.

Uhlig, S., Wollin, L., 1994. An improved set-up for the isolated perfused rat lung. Journal of Pharmacology and Toxicological Methods 31, 85-94.

Van Wyk, B.E., Gerike, N., 2000a. People's Plants, First edition, Briza Publications; Pretoria, pp. 142-216.

Van Wyk, B.E., Gerike, N., 200ob. Medicinal of South Africa, 2nd edition, Briza Publications; Pretoria, pp. 44-45.

Waithaka, J., 2004. The Evaluation of Markers for Quality Control Studies of Flavonoid - Containing Medicinal Preparations. Dissertation for the Degree of Master's in Pharmacy at the University Of The Western Cape, Bellville. 
Wang, F.M., Yao, T.W., Zeng, S., 2003. Determination of quercetin and kaempferol in human urine after orally administrated tablet of Ginkgo biloba extract by HPLC. Journal of Pharmaceutical and Biomedical Analysis 33, 317-321.

Yamazaki, M., Ueda, H., Yamazaki, C., 2002. Luteolin as an anti-inflammatory and anti-allergic Constituent of Perilla frutescens. Biological and Pharmaceutical Bulletin 25, 1197-1202. 